\title{
Algunas facetas del derecho fundamental al acceso efectivo a la administración de justicia en Colombia*
}

\section{FREDY HERNANDo TOSCANO LÓPEZ ${ }^{* *}$}

Resumen. En este escrito se analizan algunas de las cargas procesales exigidas en Colombia para acceder al proceso judicial y para ejercer el derecho de defensa, tales como las de contenido económico, la conciliación extrajudicial como requisito de procedibilidad, el cumplimiento de obligaciones contractuales y el pago del arancel judicial. El propósito de dicho examen es plantear el alcance del derecho al acceso efectivo a la administración de justicia, acudiendo para tal fin a la jurisprudencia constitucional sobre la materia. Adicionalmente, se propone que la viabilidad de la pretensión no sea tenida en cuenta para admitir la demanda, así como la existencia de un derecho a la decisión de fondo y al cumplimiento de la sentencia judicial.

Palabras clave: acceso efectivo a la justicia, cargas procesales, arancel judicial.

Fecha de recepción: 20 de febrero de 2015. Fecha de aceptación: Io de agosto de 2015.

Para citar el artículo: F. H. Toscano López, "Algunas facetas del derecho fundamental al acceso efectivo a la administración de justicia en Colombia", Revista de Derecho Privado, Universidad Externado de Colombia, n. ${ }^{\circ}$ 29, julio-diciembre de 2015, pp. 2 13-232. DOI: http://dx.doi. org/I0.18601/01 234366.n29.09

** Magíster en Derecho Privado de la Universidad Carlos in de Madrid. Miembro del Instituto Colombiano e Iberoamericano de Derecho Procesal. Profesor del Departamento de Derecho Procesal de la Universidad Externado de Colombia, Colombia. Contacto: fhtoscano.lopez@ gmail.com 


\section{Some facets of the right of access to Colombia's Legal System}

Авstract. This article examines some of the procedural burdens, such as economic hurdles, the procedural requirement of extrajudicial conciliation, the fulfillment of contractual obligations and the mandatory payment of court fees, all which one must overcome in order to access Colombia's legal system and exercise the right to defend oneself. Drawing on constitutional jurisprudence, which has addressed this matter, this article offers a rough outline of the effective right of access to justice. It also suggests that a claim's feasibility does not necessarily have to be taken into account to grant the claim and the claimant has the right to a decision on the merits of the case and the execution of judgments.

Keywords: Access to the judicial process, procedural burdens, court fees.

Sumario: Premisa. i. Las cargas procesales económicas. II. El agotamiento de requisitos previos. III. El cumplimiento de obligaciones de tracto sucesivo para ejercer el derecho de defensa. Iv. La viabilidad de la pretensión no puede erigirse en requisito de acceso a la jurisdicción. v. El derecho a la decisión de fondo. vi. El acceso a los recursos judiciales previstos. vir. El derecho a la ejecución de la sentencia. Conclusión. Bibliografía.

\section{Premisa}

En un artículo anterior se hizo un acercamiento conceptual al derecho fundamental al acceso efectivo a la Administración de Justicia (en adelante AEAJ) a partir de la teoría de la acción en sentido abstracto ${ }^{I}$. Se destacó allí que este derecho permite a cualquier ciudadano acudir a la justicia para obtener una decisión de fondo siempre que se cumplan determinadas cargas procesales previstas en el ordenamiento jurídico ${ }^{2}$.

Esto muestra que el AEAJ es un derecho en potencia, es decir, que su contenido general consiste en tener la posibilidad de acudir ante los jueces para hacer valer las propias pretensiones, por lo que al legislador procesal le estaría prohi-

I En Revista de Derecho Privado, Universidad Externado de Colombia, n. ${ }^{\circ}$ 24, enero- junio, 2007, pp. 237-257.

2 Por ejemplo, la Corte Constitucional ha precisado que el AEAJ consiste en "acudir en condiciones de igualdad ante los jueces y tribunales de justicia, para propugnar por la integridad del orden jurídico y por la debida protección o el restablecimiento de sus derechos e intereses legítimos, con estricta sujeción a los procedimientos previamente establecidos y con plena observancia de las garantías sustanciales y procedimentales previstas en las leyes”: Corte Constitucional, Sentencia C de 2002, del 29 de mayo, M.P.: Rodrigo Escobar Gil. 
bido establecer requisitos excesivos para ejercer la acción, mientras que el juez estaría obligado a interpretar y aplicar las normas procesales de manera amplia (principio pro actione), pues lo contrario vulneraría el AEAJ.

Sin embargo, esa fórmula general de garantía de acceso a la administración de justicia exige mayor precisión, la cual probablemente pueda lograrse enunciando algunas de sus principales manifestaciones o facetas concretas, las que serán propuestas en este escrito mediante el análisis de las cargas procesales que se han venido exigiendo en Colombia para acceder al proceso, tales como el pago de sumas dinerarias, el agotamiento de requisitos previos o el cumplimiento de obligaciones de tracto sucesivo para ejercer el derecho de defensa.

Adicionalmente, se pondrá de relieve que exigir la viabilidad de la pretensión para acceder a la justicia, o negar la decisión de fondo por la ausencia de requisitos procesales, son prácticas contrarias al AEAJ. También se mostrará que el acceso a los recursos judiciales previstos en el ordenamiento jurídico y el derecho a la ejecución de la sentencia se erigen en relevantes manifestaciones de dicho derecho fundamental.

El punto de partida consiste en recordar que el acceso a la jurisdicción está condicionado al cumplimiento de determinados requisitos o, en general, a la realización de alguna conducta a cargo del sujeto de derecho interesado en acudir a ella. Tales acciones son atribuidas a las partes a título de carga procesal y no de obligación, de manera que no existe un mecanismo de coerción para exigir su cumplimiento, por lo que el interés en producir el resultado (la apertura del proceso) constituye el único estímulo para su satisfacción³.

El contenido y el alcance de las cargas procesales para acceder al proceso son disímiles, por lo que se impone realizar una valoración caso a caso de ellas a fin de establecer su conformidad con el derecho al AEAJ, pues en unos eventos la carga procesal consiste en dar (realizar un pago de un arancel) y en otras consiste en un hacer (como acudir a algún mecanismo alternativo de solución del litigio). Adicionalmente y como se verá en la jurisprudencia constitucional que será citada, resulta imperativo (aunque no suficiente) que la carga procesal esté llamada a cumplir un objetivo legítimo y que no exista otra medida similar menos restrictiva del AEAJ, para que sea considerada necesaria y acorde con el mandato constitucional de garantizar este derecho fundamental.

3 Cfr. Hernando Devis Echandía, Tratado de Derecho Procesal Civil, Parte General, t. v, De la Prueba, 1967, pp. 564-565. Recuérdese que la obligación implica un "vínculo impuesto a la voluntad del obligado por un interés ajeno; vínculo cuya violación comporta una ilicitud, en cuanto es violación de un mandato que no deja al obligado libertad de elección". Mientras que la 'carga' implica la existencia de una conducta "que debe ser observada por el interesado si este quiere conseguir un fin (que) de otra manera no (sería) alcanzable”: Cfr. Gian Antonio Micheli, La carga de la prueba, trad. Santiago Sentís Melendo, reimpr., Bogotá, Temis, 2004, p. 55 . 


\section{Las cargas procesales económicas}

Por vía del ejemplo, se debe destacar que el acceso a la jurisdicción contencioso administrativa estaba sometido al requisito de que el demandante anexara, junto con la demanda, el respectivo recibo de pago de la multa o de la contribución impuesta por la autoridad tributaria, pues de lo contrario no se podía discutir judicialmente su legalidad 4 . De esta manera, en la práctica se instauraba un régimen de 'pago para ser escuchado', so pena de no acceder al proceso judicial.

Este requisito de acceso al proceso fue hallado desproporcionado al razonarse que, aunque exigir el pago del tributo perseguía un fin justificado (como es el recaudo oportuno de impuestos), este podía convertirse en un obstáculo insoslayable cuando el obligado no tuviera recursos para su satisfacción. Adicionalmente, resultaría poco razonable exigir que el deudor pague lo que precisamente quiere discutir en el proceso judicial5.

Otra carga de contenido económico se encontraba en la exigencia de una garantía (bancaria o de compañía de seguros) por un valor correspondiente a un porcentaje del impuesto en favor de la administración como requisito para que el sujeto pasivo de ella pudiera acudir a la jurisdicción contencioso administrativa para discutir su monto ${ }^{6}$. Esta carga procesal constituía un obstáculo para aquellos demandantes que no tuvieran acceso al sector financiero o que hallaran muy onerosa la constitución de una póliza de seguros, lo que en últimas resultaba atentatorio contra el AEAJ.

Y aunque esta carga procesal perseguía el objetivo de desestimular demandas temerarias y asegurar el recaudo efectivo de impuestos, resultaba exorbitante para el demandante, e innecesaria, pues existía otra medida menos gravosa que cumplía estos mismos fines: aquella que faculta al juez o magistrado para fijar una caución dependiendo de las particularidades del caso (art. I4O cca, Dcto. or de I984) 7 .

4 Esta carga procesal (declarada inexequible) se encontraba prevista en el artículo 26 del Decreto I 746 de I99 I, que establecía: "Para ejercitar las acciones ante la jurisdicción contencioso administrativa, deberá acompañarse a la demanda el recibo de pago de la multa correspondiente".

5 Corte Constitucional, Sentencia C-599 de 1992, M.P.: Fabio Morón Díaz.

6 El artículo 7 de la Ley 383 de 1997 , que modificó el artículo 867 (parcial) del Decreto 624 de I 989 (Estatuto Tributario), establecía la obligación de constituir póliza o caución cuando el monto del impuesto era igual o superior a diez millones de pesos para el año I997. Cfr. Corte Constitucional, Sentencia C-3 I 8 de i998, M.P.: Carlos Gaviria Díaz, mediante la cual se declaró la inexequibilidad del artículo $7 .^{\circ}$ de la Ley 383 de I997, que modificó el artículo 867 (parcial) del Decreto 624 de 1989 (Estatuto Tributario).

7 La Corte Constitucional, en la sentencia que se acaba de citar en el pie de página antecedente, argumentó que "requerir la constitución de un respaldo de este tipo, sin tener en cuenta las condiciones de un gran número de posibles demandantes, es un atentado contra su derecho de acción; no todas las personas tienen acceso al mercado financiero, o cumplen con la cantidad de requisitos que exigen las compañías de seguros para constituir una póliza como la que exige esta disposición". Por lo anterior, "Es imperativo que la caución, garantía o condición (de la 
De otro lado, la carga de pagar una contribución para el acceso a la justicia ha suscitado el debate en torno a la vulneración del AEAJ. En concreto, la existencia de una carga económica para dar inicio, trámite o finalización al proceso judicial (conceptualizada por la Corte Constitucional como contribución parafiscal ${ }^{8}$ ) no es en sí misma lesiva de este derecho, por lo que es su configuración concreta la que debe ser sometida a escrutinio9. De esta manera, han resultado lesivas del AEAJ determinadas regulaciones del arancel judicial, por su indeterminación, la que terminaría por afectar el derecho a la igualdad en materia tributaria y el principio de legalidad ${ }^{\mathrm{IO}}$.

El requisito de pago del arancel judicial fue objeto de análisis en razón de su especial configuración ${ }^{\text {II }}$, la que en síntesis consagraba un pago previo a la presentación de la demanda (so pena de inadmisión), dentro de cualquier proceso con pretensiones dinerarias (en los términos de su artículo 5); requisito que fuera considerado como desproporcionado al constituir una dramática intromisión

acción), sea fijada, no de antemano sino luego de admitida la demanda y repartido el proceso, para que el magistrado la ordene de acuerdo con cada caso".

8 Corte Constitucional, Sentencia C-7 I 3 de 2008, M.P.: Clara Inés Vargas Hernández. En esta providencia se estableció que el 'arancel judicial' constituye un recurso parafiscal: "Conviene precisar que si bien es cierto que originariamente las contribuciones parafiscales fueron una consecuencia de la realización de la faceta social del Estado de Derecho, ante la necesidad de acceder a los recursos necesarios para financiar renglones económicos agrícolas y ganaderos, nada se opone a que nuevos sectores sean incorporados al concepto tributario de parafiscalidad, con el fin de imponerles cargas que sean administradas por esos sectores y que redunden en su propio beneficio. Así las cosas, la Corte concluye que el arancel judicial, en los términos concebidos en el proyecto, corresponde a una suerte de recurso parafiscal".

9 "A juicio de la Corte, la existencia de aranceles judiciales no resulta per se incompatible con la Constitución, dado que corresponde a una suerte de excepción al principio general de gratuidad de la justicia que no afecta el acceso a esa función pública": Corte Constitucional, Sentencia C-7 I 3 de 2008, M.P.: Clara Inés Vargas Hernández.

Io Se trata de la declaratoria de inexequibilidad parcial del artículo $2 .^{\circ}$ del proyecto de ley reformatorio del artículo $6 .^{\circ}$ de la Ley 270 de 1996 (posteriormente, Ley I 285 de 2009). Esta norma preveía en su inciso segundo: "En los procesos contenciosos administrativos, comerciales y civiles de cuantía superior a 200 salarios mínimos legales mensuales vigentes se cobrará a cargo del demandante un arancel judicial hasta del $2 \%$ del valor de las condenas o cuantías ejecutadas en virtud de la intervención judicial, siempre y cuando el proceso se falle dentro de los términos de ley". Los reparos hallados a esta disposición consistieron en que "el inciso segundo del artículo $2 .^{\circ}$ del proyecto no permite identificar en qué tipo de asuntos se debe cobrar el arancel judicial (...) sin definir si se trata de procesos declarativos, ejecutivos, o de ambas clases [y] en este último evento, la norma omite precisar si debe pagarse el arancel tanto en la sentencia de condena como en la posterior ejecución judicial, qué ocurre en los casos en los cuales la parte se allana a las pretensiones de la demanda, o qué sucede en los procesos que concluyen por conciliación, transacción, desistimiento o cualquier otra forma de terminación anticipada. Así mismo, la norma es incierta sobre la exigibilidad o no del tributo cuando el demandante es una autoridad pública y la condena se hace a favor del Estado": Corte Constitucional, Sentencia C-713 de 2008, M.P.: Clara Inés Vargas Hernández.

I I El arancel judicial consagrado en la Ley i653 de 20 Io y que pretendía variar la regulación prevista en la Ley 713 de 2008, fue hallado inexequible: cfr. Corte Constitucional, Sentencia C-169 de 2014, M.P.: María Victoria Calle Correa. 
en los principios de justicia, equidad y progresividad tributaria. De esta manera, aun cuando la regulación del arancel se mostró ajustada a los parámetros de determinación y legalidad, fue encontrada lesiva del derecho a la igualdad tributaria por constituir una infranqueable barrera de acceso al proceso judicial respecto de determinadas personas sin capacidad de pago, como también por resultar innecesaria en presencia de otros mecanismos procesales para lograr el mismo fin ${ }^{\mathrm{I} 2}$.

\section{El agotamiento de requisitos previos}

Por razones de política legislativa que aspiran a lograr la descongestión judicial y el arreglo directo entre las partes, se ha establecido en las codificaciones procesales la carga de intentar la resolución del litigio mediante la conciliación en derecho como requisito de procedibilidad, esto es, como especie de peaje para el acceso a la función jurisdiccional.

Así por ejemplo, la celebración de una audiencia de conciliación extrajudicial en derecho se ha exigido para que pueda tramitarse la respectiva demanda de parte en determinados procesos judiciales civiles, lo que luce razonable porque siempre es deseable que las partes inmersas en un litigio intenten la resolución directa de sus controversias en pro de la descongestión judicial, y en segundo lugar, por cuanto su trámite no excluye su conocimiento ulterior por parte de la justicia.

Siguiendo este razonamiento, el requisito de estar asistido de abogado en el trámite de la conciliación extrajudicial, como requisito para acceder al proceso contencioso administrativo, no vulnera el AEAJ, en razón a que es "un medio idóneo y razonable para lograr un fin constitucionalmente legítimo, como lo es el de asegurar el cumplimiento de los principios de igualdad, transparencia y aún el de celeridad en el trámite conciliatorio" ${ }^{3}$. Sin embargo, razones prácticas, como la falta de un número suficiente de conciliadores, han hecho que se considere que la conciliación extrajudicial para acceder al proceso laboral "no puede establecerse como obligatoria y permanente (...) pues ello resulta contrario al derecho de acceder a la administración de justicia" ${ }^{4}$.

En razonamiento de la Corte Constitucional, "el arancel -en el diseño que tiene actualmentecomo instrumento para obtener recursos y disuadir la instauración de pretensiones infundadas o temerarias, es innecesaria y desproporcionada. Es innecesaria, por una parte, porque existen otros medios disponibles para impedir la interposición de pretensiones dinerarias infundadas o temerarias, dentro de los cuales se encuentran el juramento estimatorio, o las sanciones por temeridad. Asimismo, puede haber otras formas de obtener recaudos para financiar las inversiones en la administración de justicia, dentro de las cuales se encuentra por supuesto el amplio universo de posibilidades que deja la política fiscal y, en menor medida, parafiscal": Corte Constitucional, Sentencia C-r69 de 2014, M.P.: María Victoria Calle Correa.

I 3 Corte Constitucional, Sentencia C-033 de 2005, M.P.: Álvaro Tafur Galvis.

I4 Corte Constitucional, Sentencia C- I 196 de 200 I, M.P.: Alfredo Beltrán Sierra. 
De esta manera, la exigencia del agotamiento previo de mecanismos alternativos de solución de controversias no vulnera per se el contenido del derecho al AEAJ, pues para afirmar tal vulneración habría que considerar si, atendiendo circunstancias prácticas, exigir su cumplimiento podría tornarse en obstáculo injustificado para poner en marcha el proceso judicial.

\section{El cumplimiento de las obligaciones de tracto sucesivo para ejercer el derecho de defensa}

Existen también cargas procesales necesarias para el ejercicio del derecho de defensa. En concreto, puede citarse el cumplimiento de las obligaciones principales y secundarias derivadas del contrato de arrendamiento como requisito para realizar actos de defensa dentro del proceso de restitución de inmueble arrendado.

Como puede observarse, el derecho de defensa del demandado (en este caso del arrendatario) se supedita a la observancia de las obligaciones de pago de los cánones de arrendamiento ${ }^{15}$ causados antes y durante el trámite del proceso judicial. Destáquese que al analizarse si esta norma era o no compatible con el derecho fundamental al AEAJ, se encontró justificada esta carga con fundamento en que 'no hacerlo podría generar un estímulo' para que los arrendatarios no pagaran el canon mientras durara el proceso y, adicionalmente, que se dilatara la duración del proceso con el solo propósito de disfrutar el inmueble sin contraprestación alguna.

Todo lo anterior no solo iría en desmedro del derecho del demandante 'arrendador' de percibir las sumas periódicas, sino que también sería un factor de congestión judicial y de utilización del proceso judicial con fines ilegítimos. Sin embargo, al ser analizados casos concretos ${ }^{16}$, se encontró que si el juez advierte que existen serias dudas acerca de la existencia del contrato de arrendamiento, no es procedente exigir al demandado la prueba del pago del canon para ser escuchado en juicio.

De esta forma, es posible afirmar que no obstante la constitucionalidad de la norma que exige al demandado (arrendatario) el pago del canon para ser escuchado en juicio, existen casos que caen en el arbitrio judicial, en los que el juez habrá de determinar si para el caso concreto se debe eximir al demandado del cumplimiento de esta carga, por considerarla lesiva de su derecho de defensa, como cuando existen dudas acerca de la existencia del contrato de arrendamiento.

I 5 Parágrafo 2..$^{\circ}$ del artículo 424 CPP (modificado por la Ley 794 de 2003, art. 44).

I6 Ver, p. ej., Corte Constitucional, Sentencia T-ro82 de 2007, M.P.: Humberto Antonio Sierra Porto. 


\section{La viabilidad de la pretensión no puede erigirse en requisito de acceso a la jurisdicción}

Ningún juez puede realizar el análisis de las mayores o menores posibilidades de éxito de la pretensión del demandante como parámetro de admisión o de trámite del proceso judicial, de manera que existe siempre la obligación de llevar adelante el proceso, aunque luego resulte que el demandante no tenga la razón. Esta idea reafirma la autonomía del derecho de acción respecto del derecho sustancial que se pretende hacer valer, por lo que no cabría negar la apertura de un proceso $^{17}$.

Sin embargo, la práctica judicial ha demostrado que durante la calificación de la demanda, un breve examen en torno a la pretensión podría llevar a concluir que lo pretendido no tiene ningún asidero, esto es, que el ordenamiento jurídico no prohíja dicha reclamación, por lo que podría indagarse si en tales casos vale la pena tramitar un proceso que -de entrada- está llamado al fracaso, o si el juez puede rechazar la demanda por este motivo.

$Y$ es que resulta razonable que el juez haga un examen que lleve a inadmitir o rechazar la demanda pero solo por errores formales o vicios insubsanables, porque de esta manera puede adelantar el iter procesal sobre bases firmes. Pero respecto del fondo del litigio se debe reiterar que, por regla general, la reducida posibilidad de que la pretensión promovida con la demanda sea atendida no puede erigirse en fundamento para la denegación del acceso al proceso, porque en tal caso se incurriría en prejuzgamiento de la causa y se estaría vulnerando el derecho al AEAJ ${ }^{\mathrm{I}}$.

Esta regla se reitera en el ordenamiento jurídico colombiano, incluso en el caso de las obligaciones naturales, vale decir, las que "no confieren derecho para exigir su cumplimiento" I9. Pese a esta previsión normativa que supondría autorizar al juez para que no dé trámite a la demanda proveniente de una obligación natural, lo cierto es que aun en este caso debe hacerlo, por cuanto no existe una norma sustancial o procesal que le permita inadmitir o rechazar la demanda por esta causa. Adicionalmente, de lo previsto en el artículo r.528 C.C. puede inferirse que es posible tramitar una demanda fundada en una obligación natural al prever: "la sentencia judicial que rechaza la acción intentada contra el naturalmente obligado, no extingue la obligación natural”. tensión interpuesta en ella. La regla ha de ser que el juez ha de admitir todas las demandas, pues en ello está en juego el derecho de acción, constituyendo la inadmisión la forma más clara de indefensión. La decisión del juez sobre la inadmisión de la demanda puede atender a la concurrencia de los presupuestos y al cumplimiento de los requisitos procesales, pero no a la cuestión de fondo, a si la pretensión tiene o no posibilidades de éxito (salvados supuestos excepcionales)": Juan Montero Aroca, en aA.vv., Derecho furisdiccional, t. I, i $2 .{ }^{a}$ ed., Valencia, Tirant lo Blanch, 2003, p. 344.

I9 Art. I.527 C.C. colombiano. 
Existen otros casos en los que la demanda no puede proponerse objetivamente, esto es, cuando no existe ninguna norma de derecho sustancial que le sirva de asidero (de manera que quien la propone no puede invocar para sí ningún supuesto de hecho). En esta hipótesis, al juez le resulta evidente desde el inicio que la pretensión no es atendible, caso en el cual la lógica indicaría la necesidad de rechazar in limine su pretensión ${ }^{20}$. Sin embargo, una vez más, la ausencia de norma que autorice expresamente al juez para proceder de esta manera hace que este deba tramitar un proceso judicial con vocación de fracaso ${ }^{2 \mathrm{I}}$.

Distinto es el caso de las pretensiones que se promueven para la declaración o el cumplimiento de las obligaciones con causa u objeto ilícito, contrarias al orden público o cuyo objeto está fuera del comercio ${ }^{22}$. En tales casos el proceso judicial tiene que tramitarse; no obstante, en el momento en que emerja ostensiblemente el hecho que propicia la nulidad absoluta, el juez -aun de oficio- está obligado a declararla emitiendo una sentencia de fondo 23 .

En todo caso, no resulta conveniente dejar al arbitrio judicial la determinación preliminar (y caso por caso) de la probabilidad de éxito de la pretensión como requisito para el acceso a la jurisdicción, de manera que lo recomendable es que siempre exista una norma legal que expresamente excluya de la tutela judicial determinadas pretensiones por ser inatendibles, prohibidas o simplemente no prohijadas en el ordenamiento jurídico, de manera que solo en estos casos específicos sea posible el rechazo in limine de la demanda.

\section{El derecho a la decisión de fondo proscribe la sentencia inhibitoria}

Una de las más importantes manifestaciones del derecho fundamental al AEAJ consiste en el derecho a obtener una decisión de fondo, de manera que -una

20 Este sería el caso, por ejemplo, de la demanda promovida para obtener la prescripción de un bien de uso público.

2 I El Código de Procedimiento Civil solo erige causales formales de inadmisión y rechazo de la demanda, pero una interpretación amplia de su artículo 38.2 ("El juez puede rechazar cualquiera solicitud que sea notoriamente improcedente o que implique una dilación manifiesta") podría llevar al rechazo de la demanda, en aplicación de uno de los poderes de ordenación e instrucción del proceso por parte del juez. Sin embargo, el Consejo de Estado, mediante providencia 0500 I-23-3 I-000-2006-02 537-0 I, M.P.: María Inés Ortiz Barbosa, Sentencia del 28 de junio de 2007 , consideró que no es la etapa de admisión de la demanda el momento para decidir acerca de aspecto que constituyen el fondo de la litis.

22 Cfr. Jorge Peyrano, El proceso civil, Principios y fundamentos, Buenos Aires, Astrea, i 978, p. 66.

23 Artículo I.742, subrogado Ley 50 de I936, artículo $2 .^{\circ}$ : "La nulidad absoluta puede y debe ser declarada por el juez, aún sin petición de parte, cuando aparezca de manifiesto en el acto o contrato; puede alegarse por todo el que tenga interés en ello; puede así mismo pedirse su declaración por el Ministerio Público en el interés de la moral o de la ley. Cuando no es generada por objeto o causa ilícitos, puede sanearse por la ratificación de las partes y en todo caso por prescripción extraordinaria”. 
vez iniciado el proceso judicial-se espera su conclusión mediante una sentencia judicial que fije de manera precisa si las pretensiones y/o las excepciones de mérito están llamadas a prosperar ${ }^{24}$. Así pues, el AEAJ comprende el derecho a que cada una de las solicitudes que se efectúen en el curso del proceso sea resuelta, y, lo que es más importante, a que exista una respuesta motivada sobre el fondo del litigio ${ }^{25}$.

Pero no solo la ausencia material de respuesta judicial sobre el fondo del litigio genera la vulneración de esta faceta del AEAJ, porque es posible que la providencia que se emita, aunque formalmente puede calificarse como tal, se abstenga de resolver las pretensiones o las excepciones de mérito, como ocurre en el caso de las sentencias inhibitorias. Las providencias inhibitorias se fundan en que al no haberse cumplido un presupuesto procesal, le es imposible al juez decidir el litigio. En tales casos se emite una decisión formalmente denominada sentencia, pero que materialmente no decide el litigio, lo que constituye una flagrante denegación de justicia ${ }^{26}$.

Es importante aclarar que los 'presupuestos procesales' son requisitos para el surgimiento de la relación jurídica procesal, y que su cumplimiento es necesario para el inicio, desarrollo y conclusión del proceso; de ahí su importancia. Pero no se trata de requisitos fundados en el culto a la forma, sino de exigencias de la misma lógica en que se desenvuelve el proceso como instrumento para dar respuesta a una pretensión concreta. De esta manera, es lógico que la demanda esté regularmente presentada (con el cumplimiento de las exigencias legales y con una correcta acumulación de pretensiones); asimismo es necesario que exista capacidad para ser parte y capacidad procesal; y finalmente, resulta imprescin-

24 La tutela judicial efectiva en sentido amplio consiste en "el derecho fundamental al proceso jurisdiccional que dé lugar a una resolución sobre el fondo del asunto cuando concurran los presupuestos procesales y los requisitos esenciales exigidos": José Almagro Nosete, en AA.vv., Derecho procesal, t. I, Valencia, Tirant lo Blanch, p. I80. Cfr. Corte Constitucional, Auto A-077 de i999, M.P.: Carlos Gaviria Díaz, en donde, respecto de la acción de tutela, instrumento de protección de derechos fundamentales, esta Corte manifestó: "Ningún juez ante el cual se intente la acción de tutela puede abstenerse de resolver de fondo sobre el asunto planteado. Esto es, debe conceder o negar la tutela, motivando debidamente su determinación. De no hacerlo, viola el derecho fundamental de acceso a la administración de justicia y deja desprotegido al peticionario, desconociendo así el artículo 86 de la Carta”.

25 “... si el funcionario judicial competente se abstiene de responderlas [las solicitudes], tal omisión no vulnera el derecho de petición, sino que se constituye en una violación de los derechos al debido proceso y al acceso efectivo a la administración de justicia”: Corte Constitucional, Sentencia T-7 33 de 2005 , M.P.: Rodrigo Escobar Gil.

26 Estas providencias inhibitorias "permiten al funcionario salirse por la tangente, [y] son muy socorridos [sic] cuando la situación (desde el punto de vista de la aplicación de las normas sustanciales o del desarrollo de las pruebas) se muestra difícil porque sin entrar a decidir, como es su deber, dictan sentencias que le ponen fin al proceso sin dirimirlo y mostrando al juez como cumplidor de su deber por cuanto ha sentenciado, así en realidad ocurra lo contrario": Hernán Fabio López Blanco, Procedimiento civil, Parte general, t. i, 8. a ed., Bogotá, Dupré Editores, 2002, p. 967. 
dible la idoneidad del juez que conoce del proceso en términos de jurisdicción y competencia ${ }^{27}$.

Solo mediante el cumplimiento de tales exigencias el proceso judicial puede construirse sobre bases ciertas y firmes que lo lleven a una sentencia que defina el fondo del litigio. Piénsese en la inconveniencia de dar inicio y trámite a un proceso en el que no estén presentes los presupuestos anotados, pues con ello se podría ver comprometida la validez de los actos procesales realizados, lo que supondría un desgaste injustificado de tiempo y de recursos, por lo cual es necesario ejercer un control constante de los presupuestos procesales, esto es, desde la etapa de admisión de la demanda hasta antes de dictarse sentencia de fondo ${ }^{28}$.

Sin embargo, la ausencia de tales presupuestos procesales no genera por sí misma la imposibilidad de emitir una sentencia de fondo, porque a través de la conducta del juez o de las partes estos requisitos pueden superarse ${ }^{29}$. Luego la ausencia de alguno de ellos crea la obligación de aplicar remedios procesales encaminados a su subsanación, como por ejemplo la interpretación de la demanda o el requerimiento oficioso a una de las partes para que lo subsane.

Por la vía de ejemplo, puede destacarse la protección del derecho fundamental al AEAJ frente a una providencia judicial emitida por un juez de lo contencioso administrativo, en la que se abstuvo de dictar una sentencia de fondo argumentando la indebida representación de la parte demandada (esto es, de la Nación), hecho que era subsanable a la luz del artículo I40.7 CPC, pese a lo cual no fue puesta en conocimiento de las partes por el juez, quien en su lugar declaró probada la falta de legitimación por pasiva, señaló extinguido el derecho y negó las pretensiones de la demanda ${ }^{30}$.

27 Cfr. Miguel Enrique Rojas Gómez, El proceso civil colombiano, 2. ${ }^{a}$ ed., Bogotá, Universidad Externado de Colombia, p. 390. También es necesario para el inicio del proceso la adecuada representación de las partes, la correcta representación por intermedio de abogado y que la acción no esté caducada ni prescrita. Cfr. Devis Echandía, ob. cit., pp. 275-277.

28 "Los presupuestos atienden a condiciones que, si bien referidas al proceso como conjunto y no a actos procesales determinados, lo que condicionan es que en el proceso pueda llegar a dictarse una resolución sobre el fondo del asunto": Montero Aroca, en Aa.vv., Derecho furisdiccional, Parte general, cit., p. 343 .

29 "Salvo que no se cumplan los requisitos establecidos en la ley o que concurra un motivo jurídicamente válido, la inhibición en que incurre la autoridad pública constituye un comportamiento anómalo": Corte Constitucional, Sentencia su-6oo de I999, M.P.: Eduardo Cifuentes Muñoz.

30 Resulta entonces necesario "que el juez adopte las medidas de saneamiento que sean necesarias para subsanar los vicios que puedan impedir una decisión de fondo": Corte Constitucional, Sentencia T-247 de 2007, M.P.: Rodrigo Escobar Gil. Esta Corte ha afirmado en similar sentido: "La interpretación según la cual en el juicio laboral administrativo procede la sentencia inhibitoria cuando la demanda omite el cumplimiento de alguno de los requisitos de conexidad establecidos en el inciso tercero del artículo 82 del crc, vulnera el derecho de acceso a la administración de justicia”: Corte Constitucional, Sentencia T-ı 7 de 1999, M.P.: Eduardo Cifuentes Muñoz. 
A pesar de la importancia de los presupuestos procesales en la conformación de la relación jurídica-procesal y como condición para la sentencia, entender que en su ausencia solo cabe la negación de la decisión de fondo, además de ser excesivamente formalista, desconoce el derecho al AEAJ. Ello es así porque podrían intentarse otros caminos, como sería asimilar la ausencia de algún presupuesto procesal a una causal de nulidad (p. ej., las relacionadas con la falta de competencia, la incapacidad procesal y la demanda en indebida forma), las cuales ya se contemplan en el ordenamiento jurídico ${ }^{3}{ }^{\mathrm{I}}$, lo que propiciaría la ineficacia del acto viciado, y ello, a no dudarlo, es preferible a una sentencia inhibitoria.

\section{El acceso a los recursos previstos}

El ordenamiento jurídico reconoce la falibilidad del juez y por ello prevé mecanismos de impugnación o recursos ${ }^{32}$ encaminados a lograr la modificación o revocatoria de las providencias judiciales cuando en ellas se incurra en yerros de carácter fáctico o normativo ${ }^{33}$, es decir, fundados en el defectuoso entendimiento de las circunstancias de hecho que sustentan la decisión o en la aplicación de una norma (que no se encuadraba en los hechos probados) o en su deficiente interpretación 34 .

Sin embargo, se encarga al legislador establecer la procedencia de los recursos y las condiciones para su ejercicio, de manera que en este punto existe libre configuración legal35. De esta se destaca como elemento más importante

Elrecurso juctic una resolución judicial desfavorable, buscando así que la providencia se depure de los vios o desviaciones jurídicas en que se haya incurrido al proferirla": Humberto Murcia Ballén, Recurso de Casación civil, 6. ${ }^{\mathrm{a}}$ ed., Bogotá, Jurídicas Gustavo Ibáñez, 2005, p. 33.

33 "La atención sobre los recursos suele centrarse en evitar que se dicten sentencias injustas (en el sentido de no acomodadas a la realidad de los hechos o de no ajustadas al Derecho material), pero los recursos atienden también a evitar resoluciones judiciales no ajustadas al derecho procesal": Montero Aroca, en Aa.vv., Derecho Furisdiccional, cit., p. 403.

34 Miguel Rojas Gómez, Teoría del proceso, Bogotá, Universidad Externado de Colombia, 2002, p. 193. En relación con los defectos de las decisiones judiciales, vale la pena resaltar que "el juez puede incurrir en error en dos aspectos de su labor. Uno de ellos consiste en la desviación o apartamiento de los medios señalados por el derecho procesal para su dirección del juicio. Por error de las partes o propio, puede con ese apartamiento disminuir las garantías del contradictorio y privar a las partes de una defensa plena de sus derechos. Este error compromete la forma de los actos, su estructura externa, su modo natural de realizarse [...] El segundo error o desviación no afecta a los medios de hacer el proceso, sino a su contenido. No se trata ya de la forma, sino del fondo, del derecho sustancial que está en juego en él. Este error consiste normalmente en aplicar una ley inaplicable. Puede consistir, asimismo, en una impropia utilización de los principios lógicos o empíricos del fallo": Eduardo J. Couture, Introducción al estudio del proceso civil, 2. ${ }^{a}$ ed., Buenos Aires, Depalma, I953, pp. 28 I-282.

35 Así ocurre también en España, en donde se afirma que "si el legislador determina que una determinada resolución es irrecurrible esto no vulnera el derecho a la tutela judicial efectiva 
que no todo procedimiento judicial debe prever la doble instancia, de manera que la única instancia es compatible con el AEAJ ${ }^{36}$. Sin embargo, la regla general es que las providencias judiciales prevean el recurso de apelación, y que solo por excepción carezcan de ella.

Las decisiones judiciales están llamadas a su inmediato cumplimiento y sobre las mismas pesa una presunción de acierto, de manera que el ejercicio de recursos, aun cuando justificado para la eventual corrección de sus yerros, debe acompasarse con estos valores importantes para la seguridad jurídica. Por lo tanto, el mismo sistema jurídico prevé varias condiciones para su tramitación, dentro de las que se destaca: i) la procedencia del recurso (la ley establece frente a cada decisión judicial qué recurso procede); ii) la legitimación (solo la parte agraviada con la resolución judicial puede recurrirla); iii) la oportunidad (el recurso debe interponerse dentro del término legal), y iv) la observancia de determinadas cargas procesales (tales como la prestación de caución, la sustentación del recurso o el suministro de copias del expediente, etc. ${ }^{37}$.

De esta manera, le compete al juez de instancia (a quo) y al llamado a decidir el recurso (ad quem) para los casos del recurso de apelación, comprobar la concurrencia de las anteriores condiciones, erigidas para evitar que la segunda instancia se convierta en herramienta de dilación de lo decidido, así como para el correcto trámite de los mecanismos de impugnación ${ }^{3}$.

ni a un proceso con todas las garantías, a sensu contrario, resulta perfectamente constitucional": Víctor Moreno Catena, en aa.vv., Esquemas de derecho procesal civil, t. iI, Valencia, Tirant lo Blanch, 2008, p. 91.

36 En el caso colombiano se ha precisado que la doble instancia "no pertenece al núcleo esencial del debido proceso - pues la ley puede consagrar excepciones-, salvo cuando se trata de sentencias condenatorias (penales), las cuales siempre podrán ser impugnadas": Corte Constitucional, Sentencia C-345 de 1993, M.P.: Alejandro Martínez Caballero. Otro ejemplo se encuentra en Corte Constitucional, Sentencia C-71 8 del 2012, M.P.: Jorge Ignacio Pretelt Chaljub. Esta providencia declaró exequible el artículo 4, literales d y h, del Decreto 2272 de I989, normas que establecían la competencia de los jueces de familia en única instancia. En esta oportunidad, esta Corte reiteró que la doble instancia es la regla general, pero que en asuntos como el decidido su inexistencia no genera una vulneración al AEAJ. Al respecto argumentó: "[C]on la exclusión de la doble instancia en los procesos de custodia, cuidado personal, régimen de visitas y permiso de salida del país, el Legislador no incurrió en una actuación irrazonable, toda vez que la finalidad perseguida con tal excepción no fue otro [sic] que procurar en forma pronta la determinación de la situación de los niños, niñas y adolescentes frente a sus padres y frente a su salida del país. La celeridad en estos casos es un fin constitucionalmente legítimo en cuanto la dilación de situaciones de incertidumbre y conflicto, no corresponde con el deber que el Estado asume de que las medidas que se adopten o regulen frente a niños, niñas y adolescentes, respondan a su interés superior".

37 Cfr. Rojas Gómez, El proceso civil colombiano, cit., pp. 280-283.

38 Solo por vía ejemplificativa, cabe destacar algunas manifestaciones del derecho al acceso al recurso en el ordenamiento jurídico español, en el que se ha afirmado que: i) la inadmisión de un recurso judicial por causa inexistente, además de ser ilegal, atenta contra la tutela judicial efectiva (sTc 68/1983, del 26 de julio); y ii) las normas que establecen requisitos para la admisión del recurso "han de ser interpretadas teniendo siempre presente el fin pretendido 
Algunos ejemplos ilustran la necesidad de que las condiciones para el acceso al recurso sean justificadas. Así por ejemplo, en el proceso laboral se establecía que la procedencia del recurso de apelación estaba atada a que el salario devengado por el litigante superara un monto determinado ${ }^{39}$, lo cual violaba el derecho al AEAJ, al considerarse como un criterio de determinación de cuantía irrazonable e injusto, por amparar un trato discriminatorio en razón de los ingresos laborales de la parte demandante.

La carga de sustentación del recurso (exposición de los argumentos por los cuales se estima que la decisión judicial es errónea) está justificada en la necesidad de informar al juez acerca del objeto del recurso (evitando el examen de toda la resolución judicial) y permitir a la contraparte ejercer su derecho de defensa. Así pues, a fin de paliar los posibles efectos negativos de esta condición, será la interpretación pro accione del juez la que permita superar el requisito de la sustentación del recurso, como cuando el recurrente ya ha mencionado frente al a quo los argumentos para que prospere su recurso, lo cual lo relevaría de volver a hacerlo frente al juez ad quem. En la experiencia jurídica colombiana, la impugnación de la sentencia que resuelve la "acción de tutela" no requiere sustentación por su carácter preferente y sumario, luego exigirla violaría el derecho al recurso ${ }^{4}$.

En cuanto a las cargas procesales establecidas para la tramitación del recurso de apelación ${ }^{4}$, se debe destacar como requerimiento razonable a cargo del interesado el pago de las copias del expediente so pena de que se declare desierto el recurso (específicamente cuando la apelación se concede en efecto diferido o devolutivo, porque en tales casos lo actuado debe conservarse en poder del juez inferior $)^{42}$. Al respecto, se ha argumentado que, si bien esa carga procesal no afecta el AEAJ, la norma en su redacción original contenía un déficit de protección del derecho a la defensa del apelante, lo que llevó a condicionar la exequibilidad de esta norma, obligando al juez de segunda instancia a que requiera a la parte

para establecerlos, evitando que se conviertan en meros obstáculos procesales" (sTc 46/I989, y cfr. sтc 68/I983). La exigencia de una suma de dinero para acceder al recurso judicial ("depósito por vencimiento") es legítima al evitar fines dilatorios, pero la cuantía de la misma ha de ser tal que no imposibilite el derecho a impugnar. Cfr. Mauro Cappelletti, "Las garantías constitucionales de las partes en el proceso civil italiano", en Proceso, ideologías, sociedad, trad. Santiago Sentís Melendo y Tomás A. Banzhaf, Buenos Aires, Ejea, I974, p. 545.

Art. I 3 1.6.b, inc. 2..$^{\circ}$ y art. I 32.6 .3 ccA, Decreto Ley or de I984..$^{\circ}$.

Corte Constitucional, Auto 022 de I 994.

4I Art. 356 cPC.

42 El artículo 358, inciso 6. ${ }^{\circ}$, cPc, Mod., Ley 2282 de i 989, art. I. ${ }^{\circ}$, num. I 76 , establece: “Cuando la apelación que debía ser concedida en el efecto diferido o devolutivo, lo fuere en el suspensivo, el superior la admitirá en el que corresponda, y dispondrá que se devuelva el expediente al inferior, previa expedición de las copias necesarias para el trámite del recurso, a costa del recurrente, quien deberá suministrar el valor de sus expensas en el término de cinco días, contados a partir de la notificación del auto que lo admite, so pena de que quede desierto”. 
y a su apoderado a que cumplan esta carga procesal, de modo que solo en caso de que no sea cumplida se pueda declarar la deserción del recurso ${ }^{43}$.

Similares consideraciones merecería esa carga procesal aplicable a la tramitación del recurso extraordinario de casación ${ }^{44}$, aun cuando la norma que lo contempla no ha sido objeto de examen constitucional. En consecuencia, habría que ponderar el contenido de esta carga procesal frente al derecho al AEAJ en el contexto de la casación civil, a fin de establecer si en la práctica se impide su trámite (máxime cuando esos dineros pueden asumirse en cualquier momento por las partes o la misma Administración de Justicia, sin que ello cause mayor traumatismo).

\section{El derecho a la ejecución de la sentencia judicial es parte del AEAJ}

El derecho al AEAJ no cumpliría su función de asegurar la proscripción de formas no institucionalizadas de solución de conflictos si se agotara en la simple obtención de una sentencia que solucionara el litigio 45 . Por ende, es menester que el ordenamiento jurídico prevea mecanismos eficientes para que la resolución judicial se lleve a la práctica, lo que normalmente consiste en lograr que el sujeto de derecho obligado realice lo ordenado en las condiciones de tiempo, modo y lugar señaladas en la sentencia ${ }^{4}$.

Esta es la parte culminante del AEAJ, puesto que a través de ella el derecho subjetivo en litigio se trasforma en decisión judicial firme, y esta a su vez en la materialización del derecho reclamado 47 . Y es que en caso de reticencia respecto

43 Corte Constitucional, Sentencia C-83 8 de 2013 , del 20 de noviembre. M.P.: Luis Ernesto Vargas Silva. Esta providencia declaró la exequibilidad condicionada del mencionado artículo $35^{8}$, inciso 6. ${ }^{\circ}$, CPC, Mod. Ley 2282 de I989, art. I. ${ }^{\circ}$, num. I 76. Así pues, a partir de esta sentencia, "el juez de segunda instancia al proferir el auto admisorio de la apelación debe disponer que se requiera a la parte apelante para que ésta sea enterada de la carga procesal que debe asumir, y la ejecución de dicho requerimiento por el medio más expedito debe adelantarse al día siguiente de proferido el auto admisorio, justo antes de que medie la notificación por estado de esa providencia judicial. Así, se utiliza el día intermedio que fija la ley entre la expedición de la providencia y la notificación por estado de la misma, para realizar el requerimiento que garantice el derecho a la defensa previa frente a una eventual declaratoria de deserción del recurso de apelación”.

44 Art. 37 I CPC, Mod. Ley 794 de 2003 , art. 38.

45 Cfr. Almagro Nosete, ob. cit., p. I 79.

46 "El acceso a la administración de justicia, garantizado en el artículo 229 Superior (Constitución Política colombiana), no implica solamente la posibilidad de acudir ante el juez para demandar que deduzca de la normatividad vigente aquello que haga justicia en un evento determinado, sino que se concreta en la real y oportuna decisión judicial y, claro está, en la debida ejecución de ella": Corte Constitucional, Sentencia T-329 de 2004, M.P.: José Gregorio Hernández Galindo.

"El contenido principal del derecho a la ejecución consiste, pues, en que la prestación jurisdiccional sea respetuosa con lo fallado y enérgica, si fuera preciso, frente a su eventual con- 
del cumplimiento voluntario de lo ordenado en la sentencia por parte del demandado, el proceso ejecutivo ${ }^{4}$ surge como mecanismo idóneo para la obtención de tales obligaciones, aun cuando se debe advertir que contra la sentencia ejecutoriada no caben mayores medios de defensa ${ }^{49}$.

En síntesis, el derecho a la ejecución de la sentencia implica: "a) que no se creen impedimentos en el trámite de ejecución que dificulten o hagan imposible obtener lo acordado en Sentencia (...) b) que las medidas que se adopten por los órganos judiciales para ejecutar la resolución sean eficaces para garantizar la ejecución, ya que puede darse el caso de que la actividad desplegada no consiga la efectividad del fallo judicial (...) y c) el derecho a la intangibilidad de lo resuelto" $5 \circ$.

Todo ello refuerza la protección constitucional del valor jurídico de la seguridad jurídica proyectado en las sentencias judiciales y se corresponde con el valor fundamental de la cosa juzgada, límite sin el cual la resolución de los litigios no tendría fin, quedando pendiente del inicio de nuevos procesos y expuesto a fallos contradictorios ${ }^{5}$.

Otro aspecto de este derecho se relaciona con los instrumentos con los que cuenta el ordenamiento jurídico para asegurar que la sentencia dictada no sea revocada o reformada por el juez que la pronunciós ${ }^{2}$. Estos deben utilizarse como primer remedio, puesto que el juez solo puede volver sobre su fallo a fin de aclararlo, corregirlo por errores aritméticos o adicionarlo, dejando la tarea de variar su sentido a los jueces superiores a través de los recursos. Por lo anterior, el uso del recurso de aclaración ${ }^{53}$ y de otros trámites para corregir aritméticamente o adicionar la sentencia ${ }^{54}$ con miras a variar irregularmente la decisión judicial, generan indefensión respecto de quien fue favorecido con ella.

tradicción por terceros": JoAn Picó I Junoy, Las garantías constitucionales del proceso, Barcelona, Bosch, I997, p. 77.

48 "Se ha señalado en la jurisprudencia, que el mecanismo de la tutela puede ser instrumento para hacer cumplir las obligaciones de hacer, cuando se interpone en orden a garantizar la ejecución de una sentencia, pero que no es admisible frente a la ejecución de obligaciones de dar como es la situación del caso que se revisa, porque para estos eventos el instrumento idóneo de carácter ordinario es el proceso ejecutivo": Corte Constitucional, Sentencia T-67o de 1998, M.P.: Antonio Barrera Carbonell. Cfr., recientemente, el mismo sentido, Corte Constitucional, Sentencia T-599 de 2004, M.P.: Jaime Araújo Rentería.

49 Así, en el artículo 335, inciso 6. ${ }^{\circ}$ CPc, Mod. Ley 794 de 2003, art. 35, "sólo podrán alegarse las excepciones de pago, compensación, confusión, novación, remisión, prescripción o transacción, siempre que se basen en hechos posteriores a la respectiva providencia y la pérdida de la cosa debida".

50 J. Puche y L. Bertelli, El derecho a la tutela judicial efectiva (Art. 24. I CE), Madrid, Colección de Derechos Fundamentales, Fundación Jurei, 2006, p. 38.

5 I Cfr. Antonio Pérez Luño, La seguridad jurídica, 2. .a ed., Barcelona, Ariel-Derecho, I994, p. 13 .

52 Art. 309, Mod. D.E. 2282/ 89, art. r. ${ }^{\circ}$, n. ${ }^{\circ}$ I 39 CPC.

53 Previsto en el ordenamiento jurídico español.

54 Propios de los artículos 308 y 3 I 9 CPC. 
Cabe también distinguir entre las sentencias que aún no se han ejecutoriado y las que ya se encuentran en firme, porque las primeras no gozan de la garantía de ejecutabilidad hasta que se surtan los recursos ordinarios, mientras las segundas son intangibles, es decir que no pueden variarse en cuanto al fondo, salvo que se emplee el recurso extraordinario de revisión, ideado para armonizar el principio de la cosa juzgada con el valor de la justicia material.

Puesto que el derecho a obtener el cumplimiento de la sentencia puede entrar en colisión con otros derechos fundamentales, es menester realizar su análisis -caso a caso-, a fin de establecer si prevalecen los principios contrarios, tales como el derecho del deudor a conservar un mínimo económico que le permita su supervivencia ${ }^{55}$ y la inembargabilidad de ciertos bienes ${ }^{5}$. De otro lado, habrá de tomarse en cuenta la prevalencia del derecho de crédito de otros actores, por encima del crédito reconocido en la sentencia; y finalmente, el derecho de defensa del deudor (que si bien es menor por pesar sobre él una sentencia ejecutoriada, no excluye la oportunidad de proponer y probar fenómenos exceptivos como el pago, la compensación, la extinción de la cosa debida, etc.).

\section{Conclusión}

El análisis de la jurisprudencia constitucional efectuada en relación con algunas de las cargas procesales para el inicio, tramitación y finalización del proceso judicial permite mostrar algunas de las facetas concretas del derecho fundamental al AEAJ. En términos generales, este derecho fundamental prohíbe al legislador establecer requisitos excesivos para ejercer la acción, y para el juez implica interpretar y aplicar las normas procesales de manera amplia (principio pro actione).

De manera más concreta, el AEAJ impide que la carga procesal relacionada con la acreditación del pago de sumas dinerarias para la admisión de la demanda o la constitución de pólizas o garantías previas al inicio de la demanda conduzca a que en la práctica algunos sujetos de derecho no puedan ejercer su acción al encontrar un obstáculo insuperable en su situación económica.

De otro lado, el AEAJ es compatible con el pago de un arancel judicial como requisito para acceder a determinados procesos judiciales, pero siempre y cuando se cumplan determinados principios de orden tributario, como la determinación de los elementos del tributo (legalidad), la equidad y la progresividad. La conciliación extrajudicial en derecho para el acceso al proceso se considera ajustada al AEAJ, a menos que aspectos prácticos como la insuficiencia de conciliadores (como ocurre en el proceso laboral) limiten el derecho de acción.

55 STC 292/I994, del 27 de octubre.

56 "Así, la imposibilidad de ejecutar una sentencia firme por razones derivadas del derecho internacional, como es la inembargabilidad de los bienes de las sedes diplomáticas, no constituye violación del art. 24 CE (stc I 76/200 I)": Luis Díez-Picazo, Sistema de derechos fundamentales, $3 \cdot{ }^{\text {a }}$ ed., Madrid, Thomson Civitas, 2008 , p. 434. 
En cuanto a la demostración del pago del canon de arrendamiento dentro del proceso de restitución de inmueble arrendado para ejercer el derecho de defensa, se ha precisado que no puede exigirse si hay dudas acerca de la existencia del contrato de alquiler. Adicionalmente, exigir la viabilidad de la pretensión para acceder a la justicia es contrario al AEAJ puesto que el proceso judicial tiene precisamente como función la de establecer si la parte tiene o no la razón. Mientras tanto, la negación de una decisión judicial de fondo por ausencia de requisitos procesales no solo vulnera este derecho fundamental, sino la prevalencia del derecho sustancial sobre el procesal.

También se ha dejado claro que el derecho a la doble instancia no es parte de todos los procesos judiciales, pero sí constituye la regla general. Por ende, es compatible con el AEAJ la existencia de procesos judiciales de única instancia en atención a la necesidad de que tales asuntos se decidan de manera expedita.

En cuanto a las cargas procesales para obtener la tramitación del recurso de apelación, se ha encontrado que la sustentación del recurso está justificada en la necesidad de que el juez conozca las razones de la impugnación, mientras que el pago de las expensas para las copias del expediente se ajusta al ordenamiento jurídico siempre que por una providencia judicial previa se pongan de presente las consecuencias de su inobservancia.

Finalmente, se observa que el derecho a la ejecución de la sentencia implica la obligación estatal de ofrecer a la parte vencedora los mecanismos para lograr la eficacia de lo decido, siempre que tales herramientas luzcan acordes con los derechos de la parte vencida, tales como la conservación de un mínimo económico de supervivencia, la inembargabilidad de ciertos bienes y la prevalencia de determinados créditos.

\section{Bibliografía}

\section{Jurisprudencia}

Consejo de Estado, Sentencia del 28 de junio de 2007, exp. 0500I-23-3 I-0002006-02537-0 I, M.P.: María Inés Ortiz Barbosa.

Corte Constitucional, Auto A-077 de I999, M.P.: Carlos Gaviria Díaz.

Corte Constitucional, Auto I62 de 2007, M.P.: Nilson Pinilla Pinilla.

Corte Constitucional, Sentencia C-599 de 1992, M.P.: Fabio Morón Díaz.

Corte Constitucional, Sentencia C-345 de 1993, M.P.: Alejandro Martínez.

Corte Constitucional, Sentencia C-3 I 8 de I998, M.P.: Carlos Gaviria Díaz.

Corte Constitucional, Sentencia T-67o de I998, M.P.: Antonio Barrera Carbonell.

Corte Constitucional, Sentencia SU 6oo de I999, M.P.: Eduardo Cifuentes Muñoz.

Corte Constitucional, Sentencia T-ıor 7 de I999, M.P.: Eduardo Cifuentes Muñoz. 
Corte Constitucional, Sentencia C- I 196 de 200 , M.P.: Alfredo Beltrán Sierra. Corte Constitucional, Sentencia T-329 de 2004, M.P.: José Gregorio Hernández. Corte Constitucional, Sentencia T-599 de 2004, M.P.: Jaime Araújo Rentería. Corte Constitucional, Sentencia C-033 de 2005, M.P.: Álvaro Tafur Galvis. Corte Constitucional, Sentencia T-7 I 3 de 2005, M.P.: Rodrigo Escobar Gil. Corte Constitucional, Sentencia T-247 de 2007, M.P.: Rodrigo Escobar Gil. Corte Constitucional, Sentencia T-ro82 de 2007, M.P.: Humberto Antonio Sierra Porto.

Corte Constitucional, Sentencia C-7 3 de 2008, M.P.: Clara Inés Vargas Hernández.

Corte Constitucional, Sentencia C-7 r 8 de 20 r 2, M.P.: Jorge Ignacio Pretelt Chaljub.

Corte Constitucional, Sentencia C-838 de 20 I $_{3}$, M.P.: Luis Ernesto Vargas Silva. Corte Constitucional, Sentencia C-r69 de 20r4, M.P.: María Victoria Calle Correa.

\section{Doctrina}

Almagro Nosete, José. En Aa.vv., Derecho procesal, t. i, Valencia, Tirant lo Blanch, 2008.

Cappelletti, Mauro. "Las garantías constitucionales de las partes en el proceso civil italiano", en Proceso, ideologías, sociedad, trad. Santiago Sentís Melendo y Tomás A. Banzhaf, Buenos Aires, Ejea, I974.

Couture, Eduardo J. Introducción al estudio del proceso civil, 2. a ed., Buenos Aires, Depalma, I953.

Devis Echandía, Hernando. Tratado de Derecho Procesal Civil, Parte General, t. v, De la prueba, Bogotá, Temis, I967.

Díez-Picazo, Luis. Sistema de derechos fundamentales, 3. ${ }^{a}$ ed., Madrid, Thomson Civitas, 2008.

López Blanco, Hernán Fabio. Procedimiento civil, Parte general, t. i, 8. a ed., Bogotá, Dupré Editores, 2002.

Micheli, Gian Antonio. La carga de la prueba, trad. Santiago Sentís Melendo, reimpr., Bogotá, Temis, 2004.

Montero Aroca, Juan. En Aa.vv. Derecho Furisdiccional, t. I, i 2. a ed., Valencia, Tirant lo Blanch, 2003.

Moreno Catena, Víctor. En Aa.vv., Esquemas de derecho procesal civil, t. II, Valencia, Tirant lo Blanch, 2008. 
Murcia Ballén, Humberto. Recurso de Casación civil, 6. ${ }^{\text {a }}$ ed., Bogotá, Jurídicas Gustavo Ibáñez, 2005.

Pérez Luño, Antonio. La seguridad jurídica, 2. ${ }^{a}$ ed., Barcelona, Ariel-Derecho, I994.

Peyrano, Jorge. El proceso civil, Principios y fundamentos, Buenos Aires, Astrea, I 978.

Picó I Junoy, Joan, Las garantías constitucionales del proceso, Barcelona, Bosch, I 997.

Puche, J. y Bertelli, L. El derecho a la tutela judicial efectiva (Art. 24.I CE), Madrid, Colección de Derechos Fundamentales, Fundación Jurei, 2006.

Rojas Gómez, Miguel Enrique. El proceso civil colombiano, 2. ${ }^{a}$ ed., Bogotá, Universidad Externado de Colombia, 2002.

Rojas Gómez, Miguel Enrique. Teoría del Proceso, Bogotá, Universidad Externado de Colombia, 2002. 